\title{
Analysing the stability of an islanded hydro-electric power system
}

\author{
Dietmar Winkler
}

University of South-Eastern Norway, Norway, dietmar.winkler@usn.no

\begin{abstract}
Power system simulation is a large arena especially in connection with the large European power system. The challenges of large interconnected electrical power systems call for a sophisticated system modelling solution that can give comparable results. This lead to project "iTesla - Innovative Tools for Electrical System Security within Large Areas" (iTesla 2016) which was funded by the European Commission. One result of that project was the open-source modelling library called "iTesla Power System Library - iPSL" (Vanfretti et al. 2016) which then later was forked and called "Open Instance Power System Library - OpenIPSL" (ALSETLab 2018). Those libraries are based on the open-source modelling language "Modelica" (Modelica Association 2017).

This paper presents the results of a Master's thesis where Modelica was used in combination of the "OpenIPSL" library to model a small local distribution grid that is islanded.

It describes how to build the power system model using Modelica of a grid that is located in the Westfjord area of Iceland. That area of Iceland is only connected to the national grid by one transmission line. The reliability of the power supply is poor due to harsh weather conditions during winter.

Two models of the transmission system of the Westfjords were build. One is a base model with three generating units and one is an extended model with four generating units. Two different load scenarios were simulated. The result of which could give indicators as to what actions would help to keep the islanded grid stable.

Keywords: hydroelectric systems, electric power systems, modelling, modelica, open-source
\end{abstract}

\section{Introduction}

Iceland's electrical energy sector has a strong focus on renewable energy and nearly all electrical energy produced is from renewable resources. Hydro power accounts for $72 \%$ of the production. Iceland is the largest electrical power producer per capita in the world.

Being connected to the Icelandic power grid with only one transmission line makes the Westfords dependent on the internal production of the region in cases where the connection to the national grid is lost. To improve the conditions the power production inside the area needs to be increased. The largest power station in the area is Mjólká. This power station consists of 3 generating units with a ca-

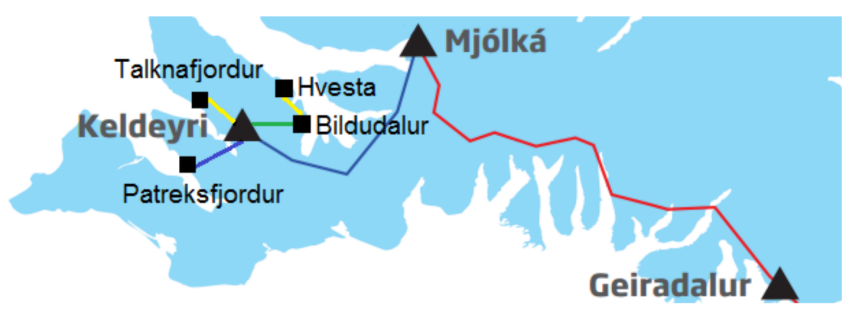

Figure 1. Overview of the transmission system with voltage levels: $132 \mathrm{kV} \quad 66 \mathrm{kV} \quad 33 \mathrm{kV} \quad 11 \mathrm{kV}$

pacity of approximately $13.2 \mathrm{MVA}$. The area is dependent on hydro power as renewable energy source for production of electrical energy as the area has little natural hot water resources for geothermal energy production.

The parts of the Westfjord transmission system including generating units, transmission lines, transformers, busses and loads were modelled using "OpenIPSL" (Open-Instance Power System Library) (ALSETLab 2018). The transmission system is simulated when the connection to the national grid is lost. As the frequency drops the individual loads are partly disconnected. It is of interest to find the disconnection sequence that gives the fastest stabilisation of frequency and voltage and what effect an additional production of a fourth generating unit, Hvesta, has on the stabilisation of the frequency and voltage.

The quality of the electricity, should be according to Regulation No. 1048/2004 on the quality of electricity and security of supply. This regulation states that the frequency shall be within $47-52 \mathrm{~Hz}$ all the time, and within $49.5-50.5 \mathrm{~Hz} 95 \%$ of the time. An internal goal of the transmission line operator Landsnet is that the frequency is within $49.8-50.2 \mathrm{~Hz} 95 \%$ of the time. The measurement used for assessing the frequency is the average frequency over a $10 s$ period. The regulation states the supplied voltage shall be within $\pm 10 \%$ of the rated bus voltage. An exception is when supplied to power-intensive industries, where the limits are $+5 /-9 \%$. This is only applicable when assessing voltage quality of $220 \mathrm{kV}$ lines, (Landsnet 2015).

\section{System description}

\subsection{Transmission system}

Figure 1 shows an part of the transmission system of the Westfjords in the northwestern part of Iceland.

This part of the transmission system consists of: 


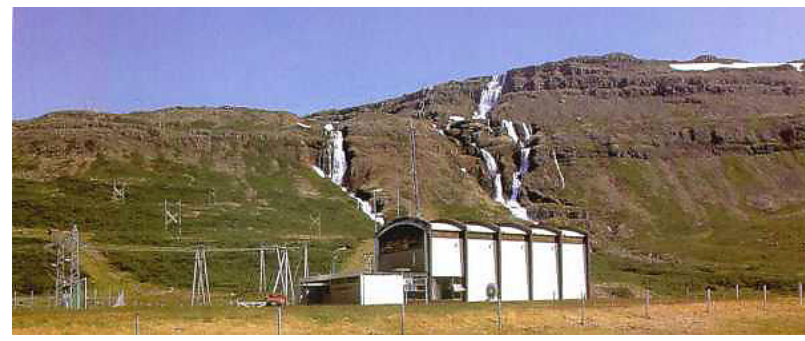

Figure 2. Power house of Mjólká 1 and Mjólká 2 (Westfjord Power Company 2018)

- Six transmission lines with different voltage levels.

- Four generating units, three at Mjólká (3.4MVA, 8.5MVA, 1.35MVA) and one in Hvesta (1.7 MVA).

- Three loads located in Talknafjordur, Patreksfjordur and Bildudalur.

The Westfjords are connected to the national grid via the Geiradalur substation. This connection is essential for the area as the internal production of all of the Westfjords only covers about $60 \%$ of the consumed power. The remaining $40 \%$ of the consumed power is imported to the area by the national transmission system from the Geiradalur substation which in turn is connected to the national high-voltage ring line.

\subsection{Mjólká power station}

The Mjólká power station, located in Arnafjordur and is the largest power station in the Westfjords, with an average yearly production of $54 G W h$. The Westfjords Power Company owns and operates the power station, which consist of three separate generating units. The first unit Mjólká 1 was built in 1956 and put into operation in 1958. Mjólká 2 was put into operation in 1975. Mjólká 1 and Mjólká 2 have a common power house, which can be seen in Figure 2.

Until 1980, when the Westfjords were connected to the national grid, Mjólká was the main power supply of the area. Mjólká 3 was constructed in 2010, and is located upstream of Mjólká 1. The recent years Mjólká 1 and Mjólká 2 have undergone turbine and generator upgrades. This led to an increased capacity of the power station by a total of $2.1 \mathrm{MW}$. All units have separate pressure shaft and utilise water from three different reservoirs. Mjólká 3 uses the reservoir of Mjólká 1 as tail water.

\section{Modelling}

\subsection{Modelica}

Modelica is an open-source high-level object-oriented, equation based modelling language for modelling of physical systems developed by the non-profit Modelica Association. The background for the development was the need for a standardised modelling language for reusable and exchangeable models. The Modelica Association has also developed a standard library which consists of more than 1600 model components within several domains. In order to utilise the language, a modelling and simulation environment is needed. There exists both open-source and commercial tools like OpenModelica (OSMC 2018) and Dymola (Dassault Systèmes 2018), respectively.

\subsection{OpenIPSL}

The OpenIPSL (ALSETLab 2018) is an open-source library for modelling of electrical power systems. It is a developed as an continuation of the iTesla project and is maintained by the ALSETLab research group. The library was used to model the following components:

- Generator

- Transformer

- Bus

- Power line

- Automatic Voltage Regulator (AVR)

- Power System Stabiliser (PSS)

- Turbine governor

The library also includes a tutorial and several application examples in addition to single components. The models are built in a drag and drop manner, setting up the models is fast and intuitive. The components are based on and validated against models from the existing power system software such as "Power System Simulator for Engineering (PSS/E)" (Siemens 2018) and "Power System Analysis Toolbox (PSAT)" (Milano 2018).

\subsection{Model of transmission system}

The model of the transmission system from Mjólká to Keldeyri consists of the four generating units Mjólká 1, 2, 3 and Hvesta, the transmission lines, the transformers and three loads. At Keldeyri the power is distributed to the loads which are located in Talknafjordur, Bildudalur and Patreksfjordur. The generating units consist of a PSS, an AVR, a turbine governor and a generator model. The Icelandic national grid is modelled as an infinite bus which is connected to the transmission line at Geiradalur. The infinite bus is a source which provides a constant voltage at a constant frequency and can provide and consume infinite amounts of active and reactive power. The model of the transmission system is made reusable so that it can be used as basis for future simulations of similar systems. All important parameters can be changed through a parameter record.

Two models of the transmission system were made, one model with the three Mjólká generating units and one extended model with an additional production from the Hvesta power station. Both are shown in shown in Figure 3 and Figure 4, respectively.

The system consists of: 


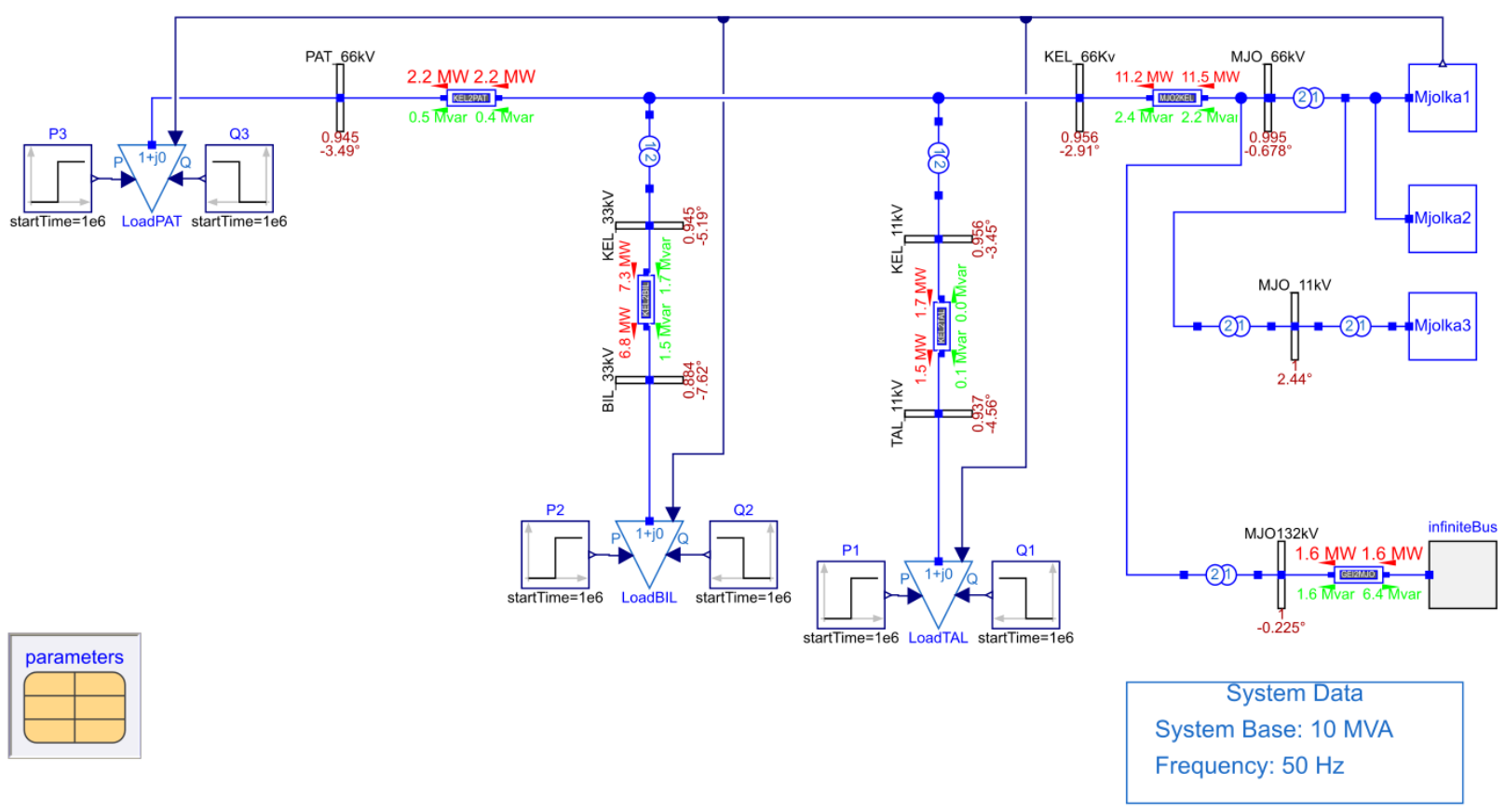

Figure 3. Three-generator model

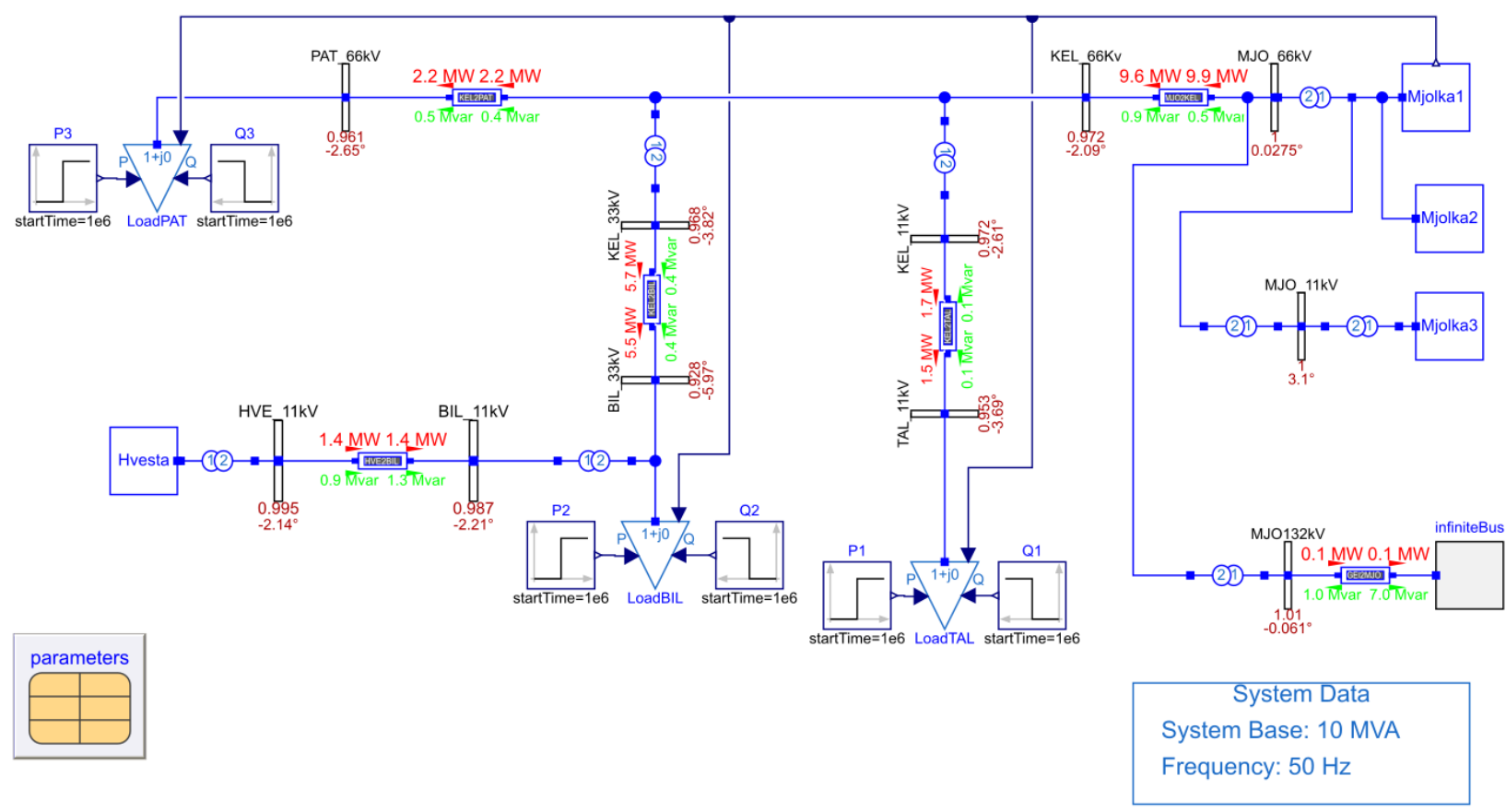

Figure 4. Four-generator model

- The transmission line from Geiradalur to Mjólká is a $132 \mathrm{kV}$ line which is stepped down to $66 \mathrm{kV}$ at the Mjólká substation and connected to the "MJO_66kV" bus where Mjólká 1, 2 and 3 are connected via a $6.3 \mathrm{kV}$ to $66 \mathrm{kV}$ transformer.

- Mjólká 3 generates at $0.4 k V$ which is stepped up to $11 \mathrm{kV}$ and is then connected to the "MJO_11kV" bus which are transformed down to $6.3 \mathrm{kV}$ and is connected with Mjólká 1 and 2.
- The Mjólká substation and Keldeyri are connected by a $66 \mathrm{kV}$ line. At Keldeyri the power is distributed to the load centres at Bildudalur, Talknafjordur and Patreksfjordur. Talknafjordur is supplied by a $11 \mathrm{kV}$ line, Patreksfjordur is connected through a $66 \mathrm{kV}$ line and Bildudalur is supplied by a $33 \mathrm{kV}$ line.

In the extended model Hvesta power station is connected to Bildudalur via a $11 \mathrm{kV}$ line.

The parameters used in the model stem from a PSS/E 
model of the Icelandic transmission system and were provided by the power company. These were used as basis for parameterisation of the models.

\subsubsection{Generating units}

The model used for the generating units consists of:

- PSAT $2^{\text {nd }}$ order generator

- PSAT Turbine governor type 2

- PSAT AVR type 3

- PSAT PSS type 2

The structure of the model is shown in Figure 5.

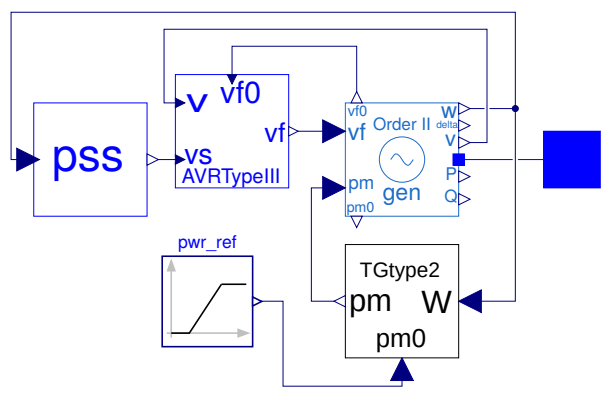

Figure 5. Generating unit model

\subsubsection{Transmission lines}

Five transmission lines are modelled in the base model and six lines in the extended model. Details and line names used in the models are given in Table 1.

Table 1. Overview of transmission lines in model

\begin{tabular}{ccccc}
$\begin{array}{c}\text { Model } \\
\text { name }\end{array}$ & From & To & $\begin{array}{c}\text { Voltage } \\
{[\mathrm{kV}]}\end{array}$ & $\begin{array}{c}\text { Length } \\
{[\mathrm{km}]}\end{array}$ \\
\hline GEI2MJO & Geiradalur & Mjólká & 132 & 81 \\
MJO2KEL & Mjólká & Keldeyri & 66 & 50 \\
KEL2TAL & Keldeyri & Talknafjordur & 11 & 9 \\
KEL2BIL & Keldeyri & Bildudalur & 33 & 13 \\
KEL2PAT & Keldeyri & Patreksfjordur & 66 & 10 \\
HVE2BIL & Hvesta & Bildudalur & 11 & 4
\end{tabular}

The parameters from the PSS/E model used a different per-unit base of $S_{B_{\mathrm{PSSE}}}=100 \mathrm{MVA}$. The models in OpenIPSL on the other hand used $S_{B_{\text {OpenIPSL }}}=10 M V A$. So all impedances needed to be corrected using (1).

$$
z_{\text {OpenIPSL }}=z_{\mathrm{PSSE}} \frac{S_{B_{\mathrm{OpenIPSL}}}}{S_{B_{\mathrm{PSSE}}}}
$$

The line parameters for HVE2BIL and KEL2TAL were estimated and were based on parameters for KEL2BIL (taken from the PSS/E reference). The reactance for KEL2BIL was calculated in $\frac{\Omega}{\mathrm{km} \cdot \mathrm{MW}}$ in order to serve for a better estimation base for the calculation of HVE2BIL and KEL2TAL.

\subsubsection{Transformers}

The PSAT two-winding transformer models were used for all transformers.

\subsubsection{Loads}

The loads used a modified version of the PSAT LOADPQ model. This is a constant load where the load amount is entered as active load in $M W$ and reactive load in Mvar.

The modifications done were:

- The system frequency and size of active and reactive loads are provided as inputs through connectors.

- A specified amount of the loads is automatically disconnected when system frequency drops below a user specified limit. Disconnected loads remain disconnected until the system frequency rises above a specified limit.

\section{Simulation of the islanded grid}

This section contains the results of simulations when the Westfjord area loses the connection to the national grid. As this happens the simulated grid operates as an islanded grid where all power consumed must be produced within the grid. It is known that the consumption of the area is larger than the production and therefore the frequency will drop after the disconnection. The voltage levels throughout the system will also be affected by less available reactive power. As the frequency drops, parts of loads in the area will automatically be disconnected at specified frequencies to maintain a balance in the consumption and production. It is of interest to see what sequence in which the loads are disconnected will give the fastest stabilisation of voltage and frequency. It is also of interest to see if the voltages and frequency are within the quality limits presented in the introduction.

Two main load scenarios have been simulated, one scenario with active and reactive loads, and one scenario with only active loads. Each scenario is simulated using both the model with three generation units and four generation units. This is done to examine what effect the additional production from Hvesta has on the stability of the system frequency and voltages compared to the model with only the Mjólká generating units. The two main scenarios are divided into sub-scenarios where different loads are disconnected to see which load gives the fastest stabilisation of system frequency and voltages. The voltages are measured at seven busses for the three generator model and nine busses for the four generator model.

All plots can be found in the appendix. 


\subsection{Scenario 1: Active and reactive loads}

The initial loads used for simulation of Scenario 1 is given in Table 2.

Table 2. Initial loads for Scenario 1

\begin{tabular}{ccc} 
Load name & $\begin{array}{c}\text { Active load } \\
{[\mathrm{MW}]}\end{array}$ & $\begin{array}{c}\text { Reactive load } \\
{[\text { Mvar] }}\end{array}$ \\
\hline LoadTAL & 2.5 & 0.1 \\
LoadBIL & 6.85 & 1.5 \\
LoadPAT & 2.16 & 0.54 \\
\hline Total loads & 11.51 & 2.14 \\
\hline
\end{tabular}

After the disconnection from the national grid the loads will be partially disconnected if the frequency drops below a specified limit. The disconnected loads remain disconnected throughout the simulation. For all simulations of Scenario 1 the connection to the national grid is lost at $t=20 \mathrm{~s}$. All generating units are running at maximum production from the start of the simulations.

\subsubsection{Scenario 1.1: Disconnection of LoadPAT and LoadTAL}

Figure 6 shows the resulting voltage and frequency plots for Scenario 1.1 simulated with the three generator model. The frequency starts to drop at $20 \mathrm{~s}$ when the connection to the national grid is lost. At $48 \mathrm{~Hz}, 50 \%$ of the active and reactive load of LoadPAT is disconnected and at $47 \mathrm{~Hz}$, $50 \%$ of the active and reactive load of LoadTAL. The frequency and voltages stabilises after $105 \mathrm{~s}$, this gives a stabilisation time, measured from time of disconnection, of $85 s$. All voltages and the frequency stabilises within the quality limits except the voltage at BIL_33kV bus which stabilises at $0.88 \mathrm{pu}$. From $20 s$ to $26 s$ all voltage levels except MJO_66kV are below the quality limit.

\subsubsection{Scenario 1.2: Disconnection of LoadBIL}

Figure 7 shows the resulting voltage and frequency plots for Scenario 1.2 simulated with the three-generator model. The frequency drops down to $48 \mathrm{~Hz}$, where $50 \%$ of the active and reactive load of LoadBIL is disconnected. The frequency and voltages stabilise after $55 s$, this gives a stabilisation time from the disconnection of $35 s$. All voltages and frequency stabilise within the quality limits. From $20 s$ to $31 s$ the voltages at all busses except MJO_66kV are below the quality limits.

\subsubsection{Scenario 1 for four-generator model}

For the four generator model, the loads of load Scenario 1 are not large enough to overload the transmission system. From Figure 8 it can be seen that the voltages and frequency are stabilised $8 s$ after the disconnection from the national grid. All voltages and frequency are within the quality limits for the voltage and the frequency except the very instance when the connection is lost.

\subsection{Scenario 2: Active loads}

The initial loads used for Scenario 2 are given in Table 3. In this scenario, the reactive parts of the loads have been neglected and the active power has been increased compared to Scenario 1. The power lines and transformers will still consume reactive power in this scenario.

Table 3. Initial loads for Scenario 2

\begin{tabular}{cc} 
Load name & Active load $[\mathrm{MW}]$ \\
\hline LoadTAL & 3.3 \\
LoadBIL & 6.85 \\
LoadPAT & 2.16 \\
\hline Total loads & 12.28 \\
\hline \hline
\end{tabular}

After the disconnection from the national grid, the loads will be partially disconnected if the frequency drops below a specified limit. The disconnected loads remain disconnected throughout the simulation. For all simulations of Scenario 2 the connection to the national grid is lost at $t=20 \mathrm{~s}$. All generating units are running at maximum production from the start of the simulations.

\subsubsection{Scenario 2.1: Disconnection of LoadPAT and LoadTAL}

Figure 9 shows the resulting voltage and frequency plots for Scenario 2.1 simulated with the three-generator model. At $48 \mathrm{~Hz}, 50 \%$ of the active load of LoadPAT is disconnected and at $47 \mathrm{~Hz}, 50 \%$ of the active load of LoadTAL. The frequency and voltages stabilises after $75 s$, this gives a stabilisation time from the disconnection of $55 s$. All voltages and frequency stabilises within the quality limits. From $20 s$ to $34 s$ the voltages of TAL_ $11 \mathrm{kV}$ and BIL_33kV busses are below the voltage limits.

Figure 10 shows the resulting voltage and frequency plots for Scenario 2.1 simulated with the four-generator model. At $48 \mathrm{~Hz}, 50 \%$ of the active load of LoadPAT is disconnected.

For this simulation LoadTAL does not need to be disconnected to stabilise the frequency and voltages. The frequency and voltages stabilises after $90 \mathrm{~s}$, which gives a stabilisation time from the disconnection of $70 \mathrm{~s}$. All voltages and the frequency are within the quality limits, the voltage levels are higher than for the three-generator model

\subsubsection{Scenario 2.2: Disconnection of LoadBIL}

Figure 11 shows the resulting voltage and frequency plots for Scenario 2.2 simulated with the three-generator model. The frequency drops down to $48 \mathrm{~Hz}$, where $50 \%$ of the active load of LoadBIL is disconnected.

The frequency and voltages stabilises after $50 \mathrm{~s}$. This gives a stabilisation time from the disconnection of $30 \mathrm{~s}$. All voltages and the frequency stabilise within the quality limits. All voltage levels except $\mathrm{MJO}$ 666kV are below limits in the time between $20 s$ to $27 s$. 
Figure 12 shows the resulting voltage and frequency plots for Scenario 2.2 simulated with the four-generator model. The frequency drops until $48 \mathrm{~Hz}$, where $50 \%$ of the active load of LoadBIL is disconnected. The frequency and voltages stabilises after $70 \mathrm{~s}$. This this gives a stabilisation time from the disconnection of $50 \mathrm{~s}$. All voltages and frequency stabilise within the quality limits. The voltages at MJO_66kV and HVE_11kV bus are above limits in the time between $47 s$ to $51 s$ and TAL_ $11 \mathrm{kV}$ is below the limits at $54 \mathrm{~s}$.

\section{Discussion}

\subsection{Summary Scenario 1}

The additional production of Hvesta, manages to keep the system stable after the disconnection. For the three generator model the disconnection of LoadBIL gives the best results. The system stabilises faster, and all voltages stabilises within $\pm 10 \%$ of the rated voltage. At steady state before the disconnection it can be seen from both simulations of the three generator model that the voltage at BIL_33kV is too low, this can be regulated locally for example by a tap changing transformer.

\subsection{Summary Scenario 2}

The additional production of Hvesta, causes the fourgenerator model to stabilise slower than the three generator model, as the frequency will drop slower. The fourgenerator model gives more stable voltage at the busses compared to the three generator model. The disconnection of LoadBIL gives the fastest stabilisation for both models.

\subsection{Modelling challenges}

Due to difficulties simulating the transmission system after losing the connection to the main grid using the load parameters as used in the PSS/E model, the size of the reactive load had been reduced in the simulations. For the same numerical reason the transformers reactance is assumed to be less than what is used in PSS/E. This can lead to inaccuracies in the simulation results of voltage levels at the busses compared to reality, where the voltage levels probably will be somewhat lower than what is shown in the simulations of Scenario 1. Still the simulations will give a good indication of the time it will take for the voltage levels to stabilise.

For the active power and the frequency this will give more accurate results, as the parameters used are equal to the PSS/E model for the active loads. The assumed turbine governor parameters are not good enough in cases where a large amount of the load is removed. The governor struggles with decreasing the production enough to allow the frequency to stabilise at $50 \mathrm{~Hz}$. It can be assumed that with correctly tuned controls the frequency would settle at $50 \mathrm{~Hz}$ not at $50.2 \mathrm{~Hz}$.

\section{Acknowledgement}

This paper is based on the Master's thesis by Kim Aars with the title "Simulation of load and fault scenarios in a hydro power system with island grid" (Aars 2017) finished in May 2017 at the University College of Southeast Norway.

This project was carried out in collaboration with Verkís Consultant Engineers, Iceland.

\section{References}

Aars, Kim (May 31, 2017). "Simulation of load and fault scenarios in a hydro power system with island grid". Master's thesis. University College of Southeast Norway.

ALSETLab (2018). OpenIPSL. URL: http : / / openipsl.org.

Dassault Systèmes (2018). Dymola. Modelon. URL: http : / / www . dymola . com (visited on 05/28/2016).

iTesla (2016). iTesla - Innovative Tools for Electrical System Security within Large Areas. URL: http: / / www . itesla-project.eu/.

Landsnet (2015). Landsnet Performance Report 2015. URL: http : / / 2015 . landsnet . is / wp content / uploads / 2016 / 05 / Landsnet _ USE_performance_report_2015_englishFINAL_26-5-2016.pdf (visited on 08/31/2018).

Milano, Federico (Aug. 31, 2018). PSAT. URL: http : //faradayl.ucd.ie/psat.html.

Modelica Association (Apr. 2017). Modelica - A Unified Object-Oriented Language for Systems Modeling. Language Specification Version 3.4. Tech. rep. Linköping: Modelica Association. URL: https : / / www . modelica . org / documents / ModelicaSpec34.pdf.

OSMC (Aug. 31, 2018). OpenModelica - open-source Modelica-based modeling and simulation environment. Ed. by Open Source Modelica Consortium. URL: https://openmodelica.org/.

Siemens (Aug. 31, 2018). PSS/E. URL: http : / / siemens . com / power - technologies / software.

Vanfretti, L. et al. (2016). "iTesla Power Systems Library (iPSL): A Modelica library for phasor time-domain simulations". In: SoftwareX 5, pp. 84-88. DOI: 10 . 1016/j.softx.2016.05.001.

Westfjord Power Company (Aug. 31, 2018). Mjolka (Milk) River Power Station. URL: https : / / ov . is / en.

\section{A Appendix}



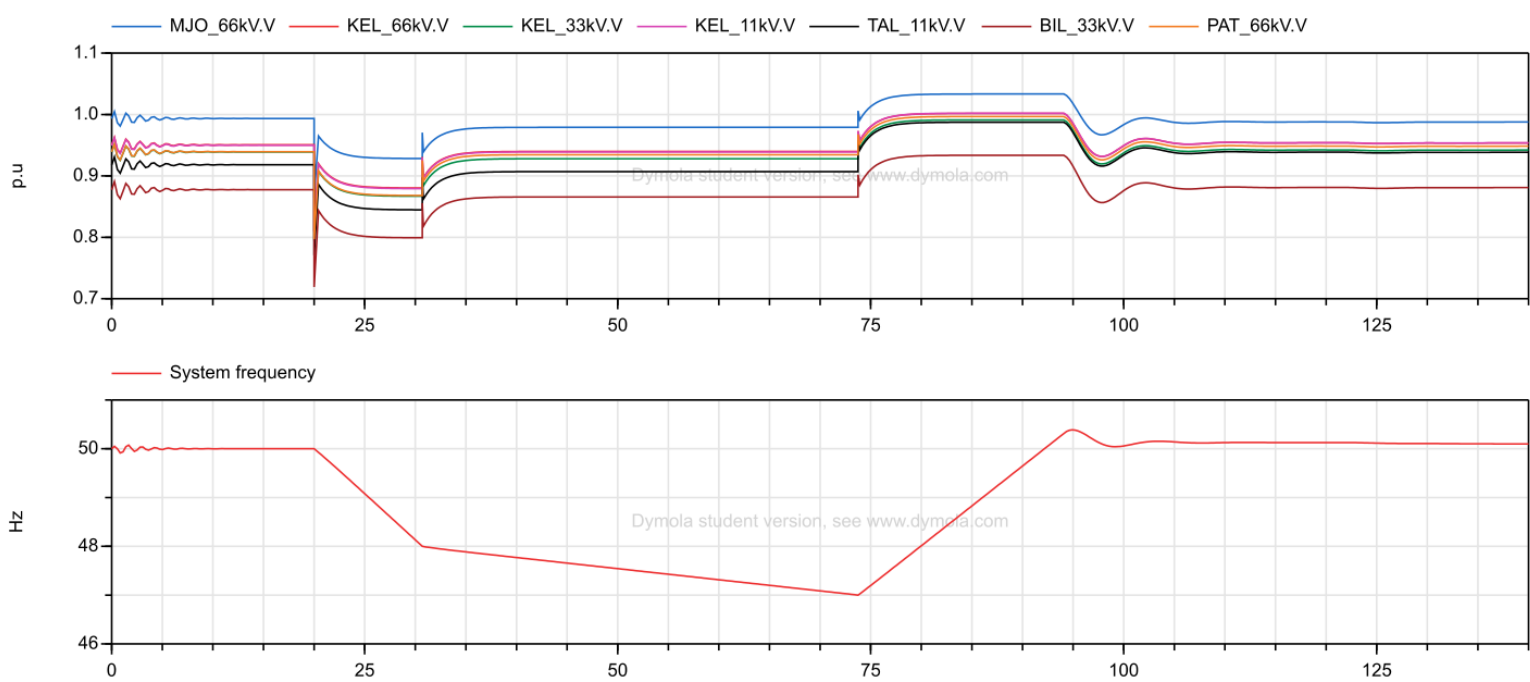

Figure 6. Voltage and frequency plots for Scenario 1.1 for the three-generator model
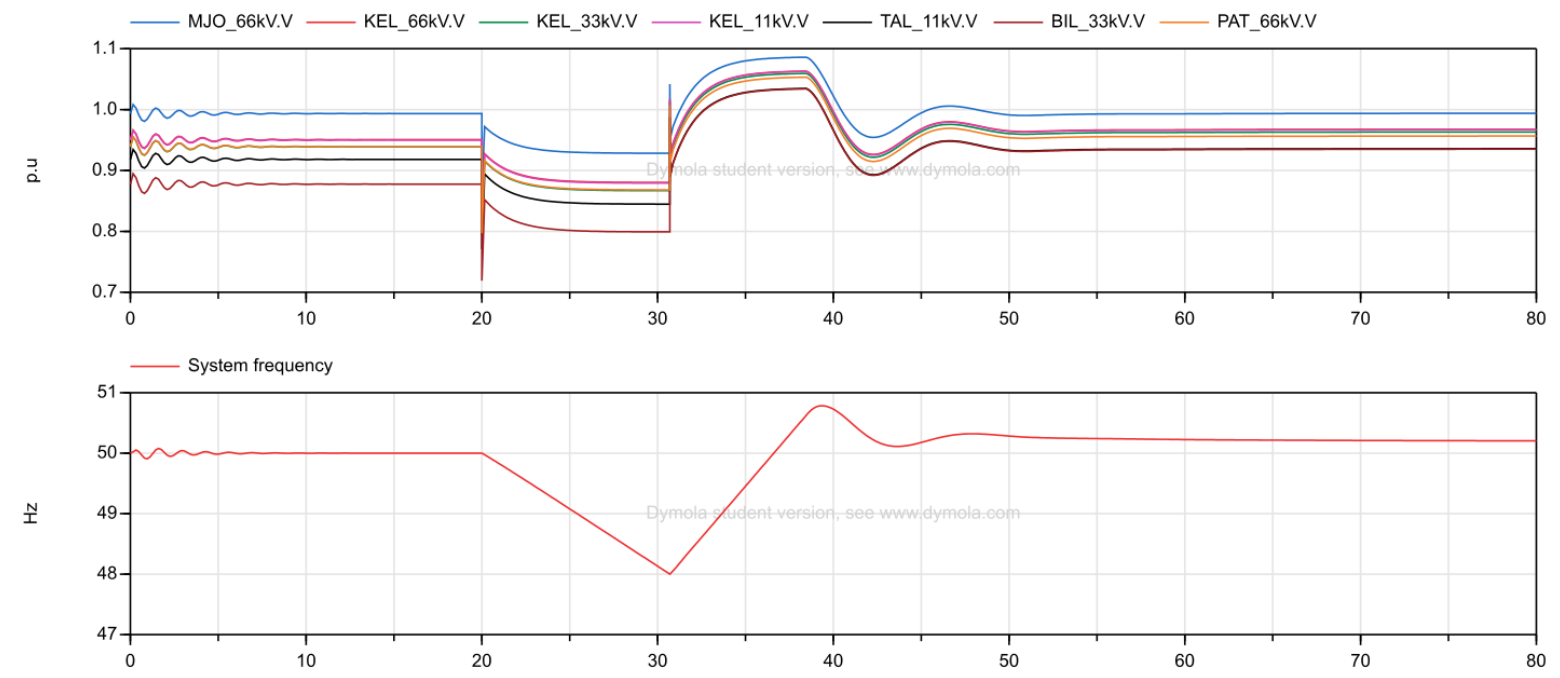

Figure 7. Voltage and frequency plots for Scenario 1.2 for the three-generator model
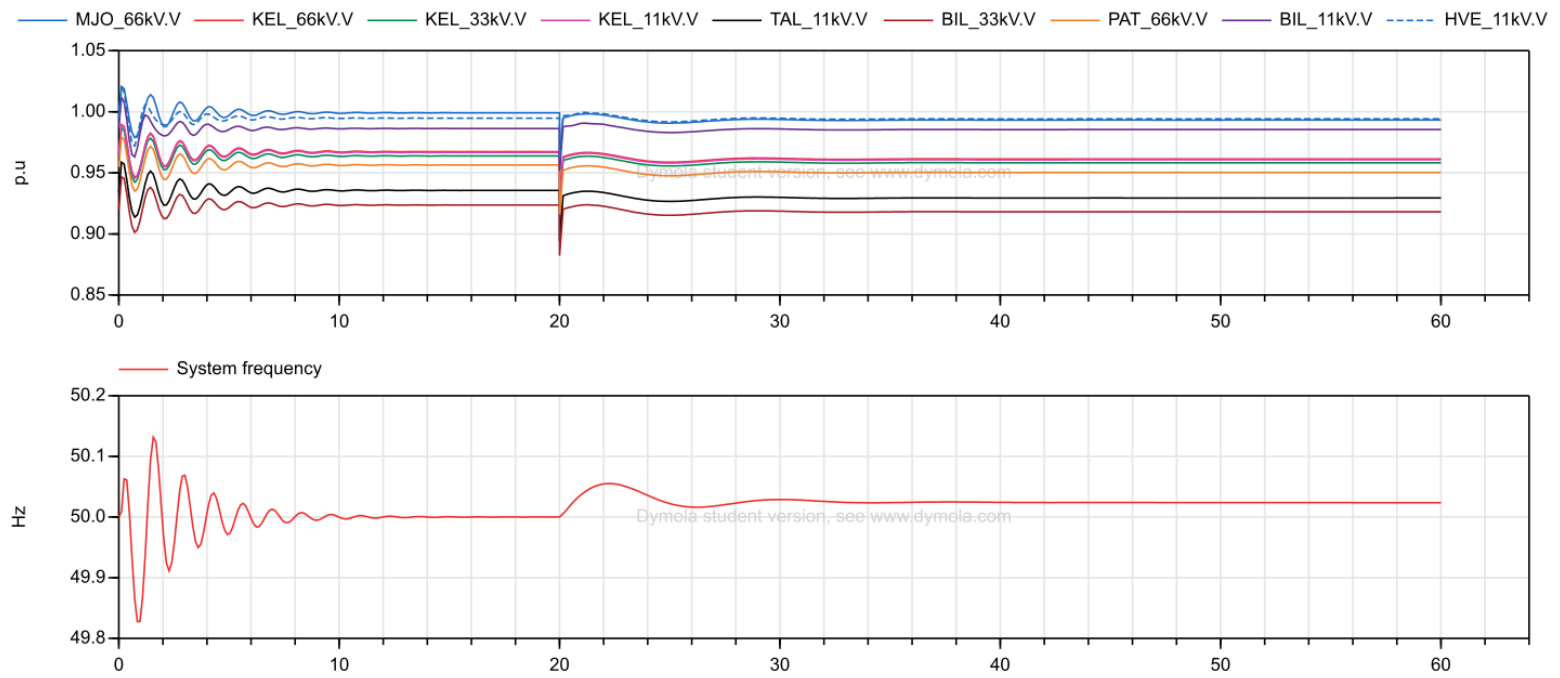

Figure 8. Voltage and frequency plots for Scenario 1 for the four-generator model 

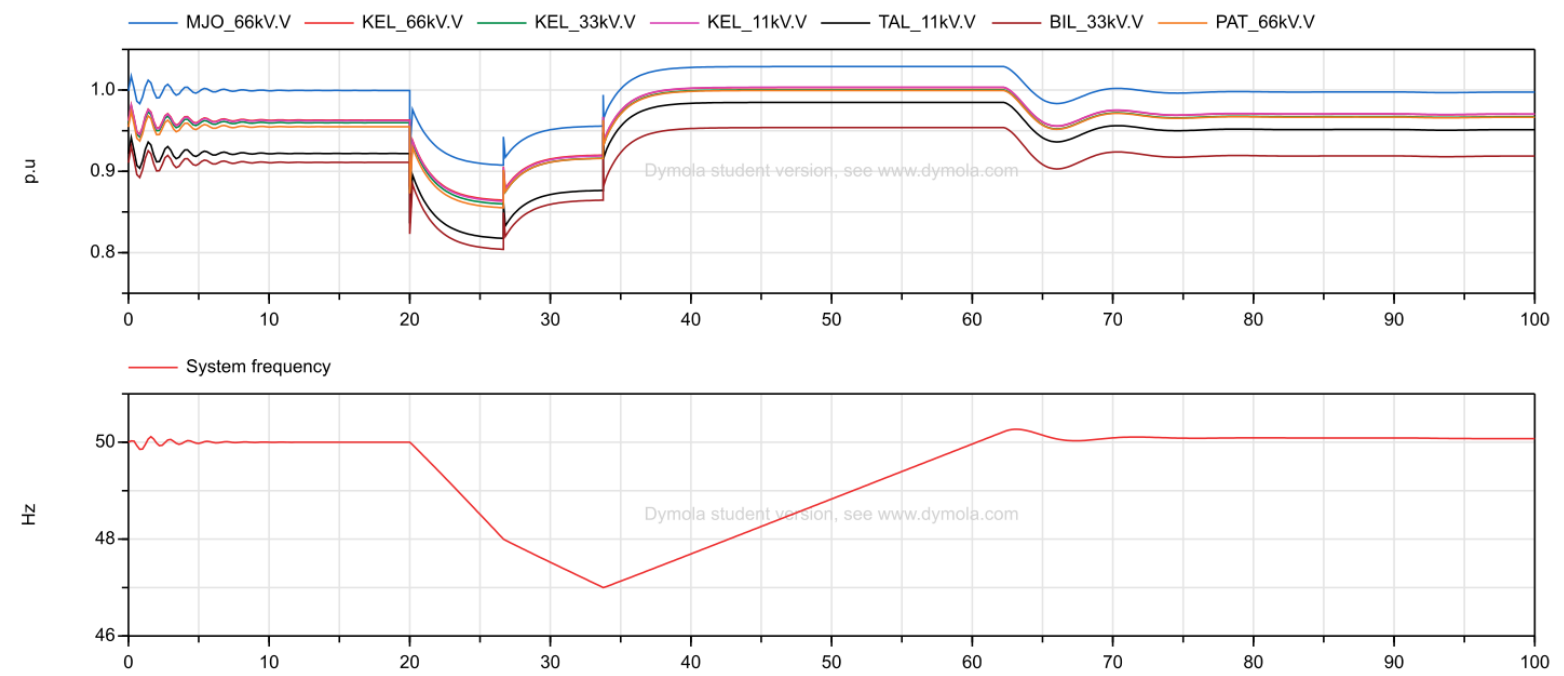

Figure 9. Voltage and frequency plots for Scenario 2.1 for the three-generator model
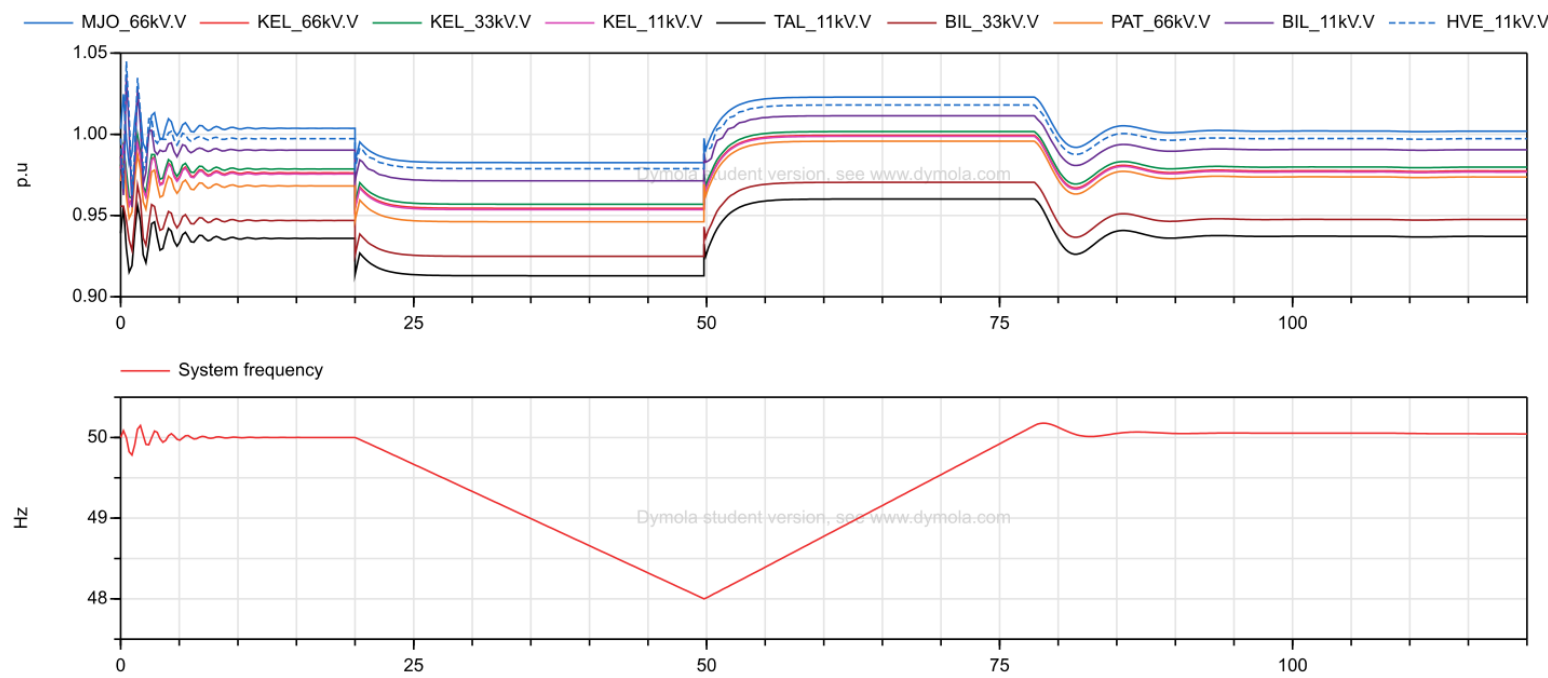

Figure 10. Voltage and frequency plots for Scenario 2.1 for the four-generator model
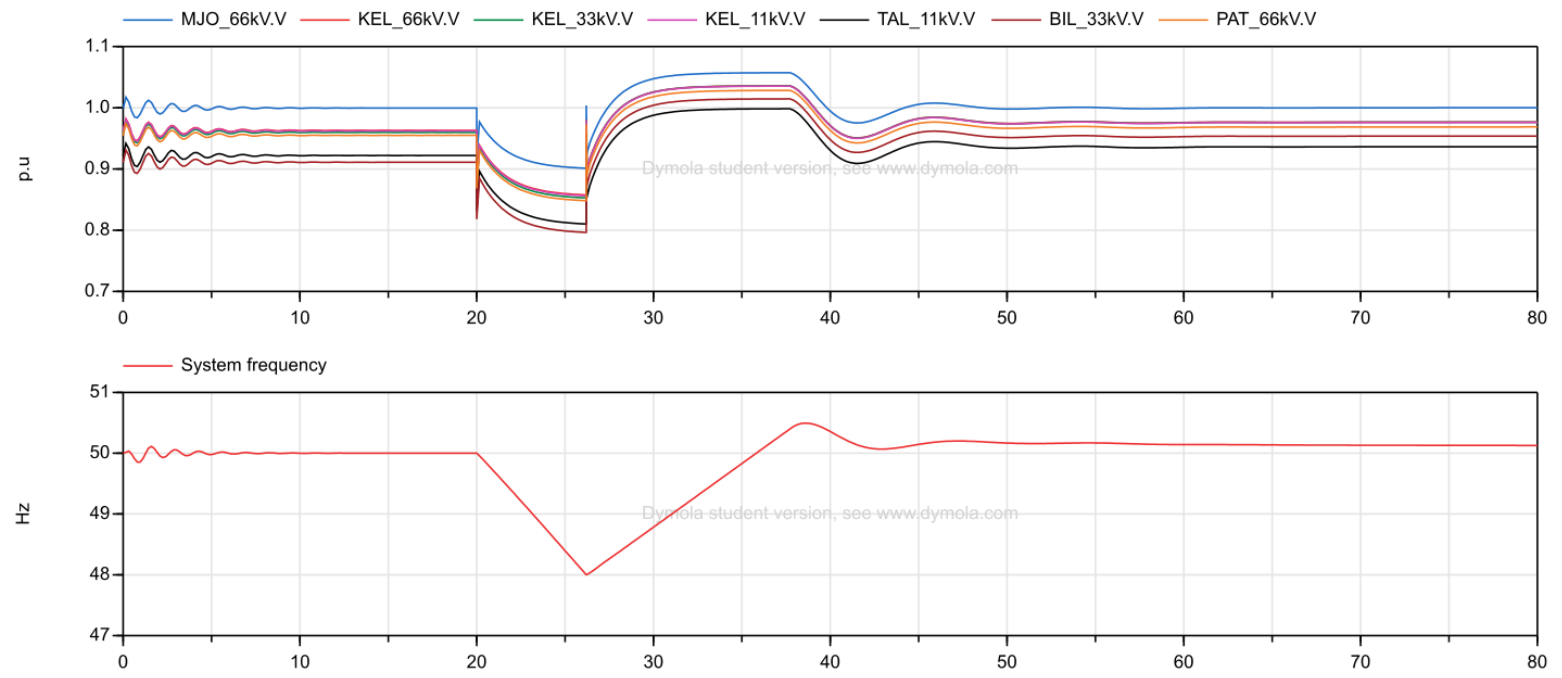

Figure 11. Voltage and frequency plots for Scenario 2.2 for the three-generator model 

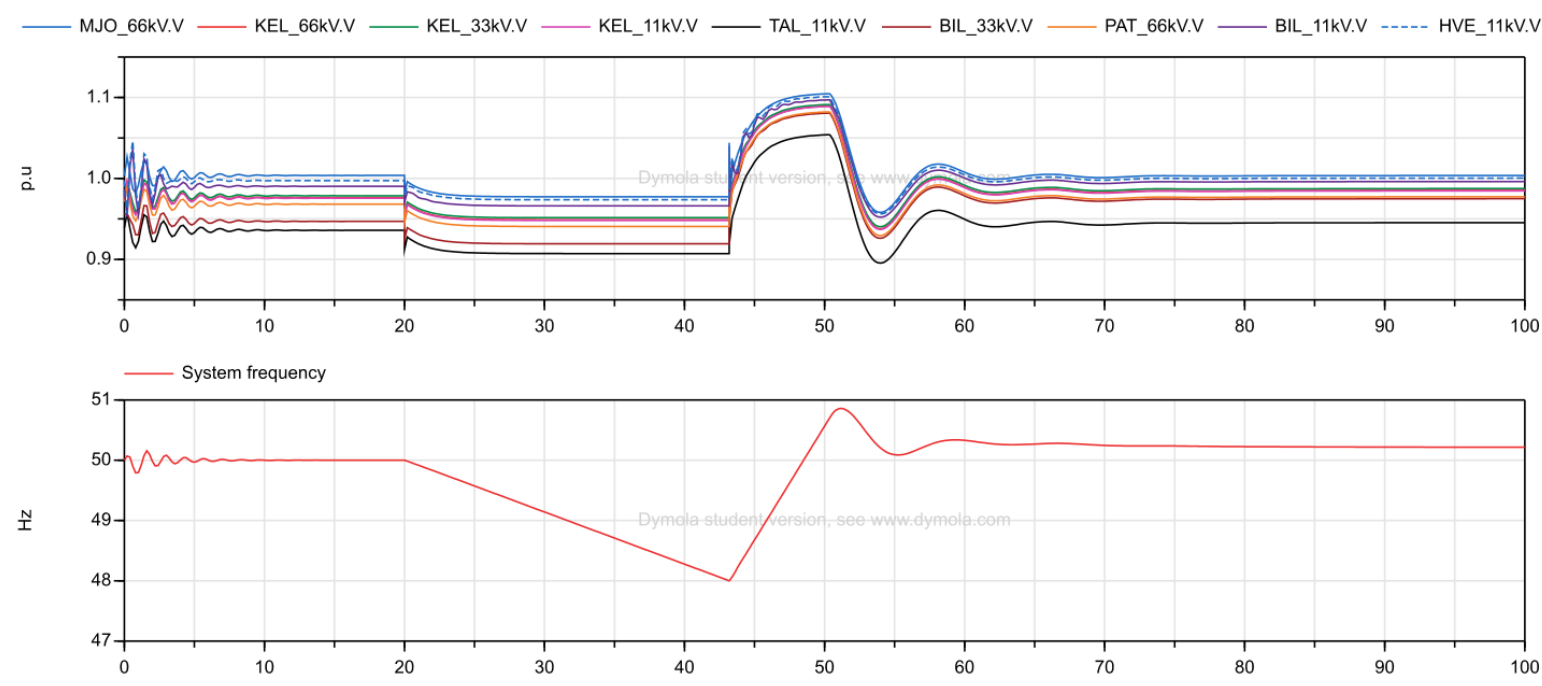

Figure 12. Voltage and frequency plots for Scenario 2.2 for the four-generator model 